КУВАКОВА Ирина Михайловна - кандидат социологических наук, доцент Российской академии предпринимательства (109544, Россия, г. Москва ул. Малая Андроньевская, 15; kuvakovaim1999@ mail.ru)

УСТИНКИН Сергей Васильевич - доктор исторических наук, профессор; декан факультета международных отношений, экономики и управления, профессор кафедры международных отношений и политологии Нижегородского государственного лингвистического университета им. Н.А. Добролюбова (603155, Россия, г. Нижний Новгород, ул. Минина, 31а); директор Приволжского филиала ФНИСЦ РАН (603000, пер. Холодный, 4; sv.ustinkin@gmail.com)

\title{
ЯЗЫК КАК ИНСТИТУТ И ИНСТРУМЕНТ УМО- И САМОСТРОЕНИЯ БУДУЩЕГО МИРА
}

Аннотация. В представленной статье язык рассматривается как механизм социальной самоорганизации. Слово лежит в основе формирования человеческих отношений, правил соседства и социальных практик. Авторы анализируют проблему лингвистической безопасности и связанные с ней аспекты развития общества.

Ключевые слова: лингвистическая безопасность, язык, смысл, социальные процессы, политический процесс

B глобальном, переменчивом и «текучем», но предельно концентрированном пространстве-времени и, вопреки некоторым представлениям, зависящем от смыслов, идей и человеческого выбора мире острейшим образом стоят проблемы известных явлений, таких как понимание самих себя и ближнего, многонациональное со-бытие, принятие и уважение «чужого», права и свободы, совестливость, ответственность и доверие, справедливость и «общее благо», или необъятный и необозримый «космос» вопросов, имеющих грандиозный потенциал судьбоносного выбора пути в будущее, тем научных исследований, феномена умо- и самостроения человеческого духа и развития общества.

\section{Язык как институт народного единства}

Известное многообразие попыток изучения народных характеров и их природы, основ и логик социально-исторической самореализации (философия, естествознание, история, география, психология), смыслоценностных и речевых актов (риторика, лингвистика, морфология, орфография, фонетика), языковой, вербальной (и невербальной), трансментальной и информационной коммуникации, наконец, индивидуальной, этнической и национальной, гражданской, государственной, или «коллективной» безопасности есть объективированная копия, слепок социокультурной среды, «продукт», создаваемый человечеством на протяжении веков, в т.ч. при непосредственном взаимодействии деятельных людей и соорганизации масс. Это априори есть «продукт», результат многолетних усилий создания общественных условий (экономика, социология, политика, педагогика, конфликтология, управление), которые, как справедливо оценивается, привели «целое», цивилизацию планеты к современному состоянию глубочайшей за все времена расколотости [Иноземцев 1999]. С другой стороны, этот многомерный и усложняющийся комплекс явлений - итог духовной и мыслительной (интеллектуальной) работы, череды «правильных» и «ложных» актов выбора смыслов, ценностей и направлений жизнедеятельности, плод действия объективных закономерностей феномена социальной самоорганизации, являющего тесную связь первоначал (энергий, воль, целей) и содержания материи современного наследия - блага человека и общества. 
Здесь существенными факторами являются традиции и новые течения познавательной, религиозной и культурной мысли; содержание мировоззренческих (аксиологических, идейных, идеологических) устремлений, практика научнообразовательной, экономической и производственной деятельности; технические, технологические, демографические, геополитические, военные, ИКТ (IT) и другие вызовы. Об этом свидетельствует достигнувшее беспрецедентного уровня влияние на умонастроения людей, народов разных стран современных СМИ, $T V$ и Интернета, довлеющих над душой человека и судьбоносным выбором целых обществ. В основе мощных воздействий и их социального эффекта лежит либо благоприятный миф, научный прогноз, либо множество эсхатологических сценариев, разыгрываемых часто с использованием малопригодных средств и влияний на ограниченный запас потенций, ресурсов и возможностей решения стоящих перед обществом и миром болезненных проблем.

Лучшим выходом из осознаваемого тупика - понимания лавинообразного роста трудных вопросов и конфликтов - является личностное и национальное самоосознание, понимание своей миссии, социальной роли и места в подлунном мире; необходимость следования путем конструктивно-взвешенного выбора - не «флюгерного», двойных (тройных) стандартов, компрадорского или какого-либо еще, не исключительного (за счет других, малых народов), а собственного, желательно реального, созидательного, перспективного и вместе со всеми самоустроения - признака особой жизненной силы, народного (национального) достоинства и волевой несгибаемости, исключительной общей выгоды движения вперед.

Однако предлагаемое в силу либо определенных и ясных для большинства, либо понятных только избранным обстоятельств многообразие картин прошлого и современного мира повседневно, методично и направленно контролируется смысловым, идеологическим контентом (тексты, графическая и звуковая информация, книги, газеты, рейтинги, данные исследований, big data, пр.), который управляет не только внутренним самоощущением людей, но и их пониманием и решениями, «облаками» межличностного, межнационального общения, государственных и межстрановых отношений. Предложения действовать не по своему усмотрению, а так, как «должно быть», транслируются через примеры доминирования и приманку неясных демократических преимуществ, образцы жесткой риторики и непартнерского поведения (последний пример дипломатический демарш западных стран против России). Вся мощь навязываемых способов «идеальной» идентификации и подачи информации редко независимых и чаще ангажированных информационных ресурсов направляется на углубление и обострение ложных идей противостояния, не замечая отчетливо прослеживающиеся на протяжении тысячелетий признаки смыслозначимых ориентиров сходства и естественной близости, а с другой стороны - нивелирующих многовековые принципиальные и непримиримые различия, антагонизм. Все эти моменты феномена социальной самоорганизации выходят за пределы действия естественных закономерностей и подпадают под искусственное влияние энергий и сил, формируемых многоуровневым - «точечным», локальным и тотальным - влиянием глобализации

\section{Институциональный контент европейской цивилизации}

Особенностью стержневого контента, ресурса, начиная с древности, и не утратившего своего сакрального и всеобъемлющего значения знания сегодня, является «логос» - слово, мысль, смысл, число... Как носитель особой генетики цивилизационного умо- и самостроения, самоорганизации людей и учреждаемой ими общности, понятие древнегреческой философии «логос» 
(высказывание или суждение, речь) имеет глубинное и преображающее влияние. Это следует из многочисленных и разноплановых примеров, демонстрирующих целые пласты сменяемых характеристик институциональных образований, а в целом - образцово схожих общественно-экономических укладов: человеческого самоприсутствия во всех начинаниях, непреходящих ценностях и многовековых жизненных ориентирах, отображаемых в образах, мифах, примерах и картинах мира, участвующих в свободных (или нет) актах волевого исторического выбора и героической или бесславной судьбе народов. Оно было привнесено в познавательный оборот древнегреческим философом Гераклитом (544-483 гг. до н.э.), известным как Мрачный, или Темный (у Аристотеля). Основатель первой исторической (первоначальной) формы диалектики рассматривал и строил свои рассуждения, используя термин «логос» в объединяющем значении «вечной и всеобщей необходимости», вмещающей естество смыслоценностного и «устойчивой закономерности», самоорганизации и жизненности мироздания, земного и космического «со-бытия», обыденного и вечного пути человечества.

Мифология Античности предложила «идеальные» примеры форм само- и мироустроения - смыслы, язык, письменность и содержание мировоззрения человека; обрядами, ритуалами и традициями заложила формализованные нормы отношений, принципы соседства, правила общежития и социальные порядки. Вся многослойная духовная и интеллектуальная жизнь общества, этика и эстетика как синтез ценностей и культур участвовали в создании полисно-государственных укладов ${ }^{1}$, неотделимых от вечных, вневременных смыслов и повседневных, рутинных деяний, мыслей и трудов людей и народов, пронизывающих всеобщность, целостность главных элементов, гуманистических доминант понимания бытия и небытия - схоластики, философии, теологии, экономики, политики и пр.; деловых связей - ремесел, производства, искусств и обмена; веры и неверия, безмятежности и страха, добра, ненависти, мира и войны. Инструментальные основы умо- и самостроения, «самостояния» («...На них основано от века / По воле бога самого / Самостоянье человека / Залог величия его» [А.С. Пушкин]) находятся в анналах памяти - национальном коде и автохтонном наследии народов, устной и летописной истории.

В древней Греции и Риме писали на папирусе и пергаменте, соединяли листы в компактные «тетради» и получали «том», или «кодекс». Считается, что именно здесь родилось слово «библиотека»: «библос» - книга и «теке» - склад, хранилище; отсюда и название «Библия». Самые ранние сведения об институциональных основаниях общественных образований и языкознания пришли из библиотек и относятся ко II тыс. до н.э. Создателями и обладателями библиотек c VI-IV вв. до н.э. были правители и философы - Пифагор, Платон, Аристотель - или, например, государственный деятель, оратор и писатель, организатор первой римской публичной библиотеки Азиний Поллион (І в. до н.э.).

Афинская библиотека в Акрополе помещалась вместе с государственными службами, картинной галереей и казной. Греческий ученый-математик Демосфил трудом «О книгах, достойных приобретения» создал первый библиографический указатель. Библиотека Аристотеля в афинском Ликее, где философ читал лекции, насчитывала десятки тысяч свитков. В ее организации принимал участие и Александр Македонский - воспитанник Аристотеля. После Аристотеля (321 г. до н.э.) библиотека стала частью особого комплекса - Мусейона (храма муз), созданного Теофрастом (Феофрастом), прозвище которому дал Аристотель, которое, как считалось, означало «Богоречивый».

\footnotetext{
${ }^{1}$ Полис - город-государство.
} 
Покидая Афины, Аристотель передал управление Ликеем Теофрасту, 35 лет бессменно руководившему школой, где находились залы для бесед и чтения лекций, жилые помещения для преподавателей и сад для познавательных прогулок и бесед. В эпоху эллинизма систематизировался опыт и накопленные за тысячелетия знания: только одна Александрийская библиотека насчитывала около 700000 рукописей в свитках папируса и пергамента; здесь развивались новаторские для того времени и бесконечные по потенциалу направления познания, ставшие прародителями современных наук - математики, логики, астрономии, геометрии, биологии, медицины, управления...

Античная Греция через «логос», коренные основания бытия (и небытия) особым образом «просеяла» предшествующий опыт поколений и зафиксировала фундаментальные основы - идеи и учения, модели и механизмы, институты и способы социальной самоорганизации - от зарождения, становления, селекции и укоренения (или редких отказов) до методов и моделей, уровней и ступеней, циклов и волн развития (или, напротив, дефрагментации, стагнации, разрушения), включая накопление и формализацию. Универсализация и изменение понятий (терминов, категорий) и расшифровка смыслов, значения и ценностных кодов как общежитейских, предприимчивых, деловых и государственных, гражданских ориентиров человеческого бытия, расширяли и ускоряли возможности познания, понимания полезного и вредного, опасного знания, их общезначимых восходящих и нисходящих движений. Мудрецы, социальные мыслители и философы, естествоиспытатели, общественные и политические деятели, художники, литераторы и правители - главные духовные движители эпох - добросовестно и вполне успешно выполнили добровольно взятую на себя особую миссию.

Античность - «колыбель европейской цивилизации» - являет неисчерпаемый, необъятный источник достижений, смыслоценностных практических, этических и эстетических образцов, примеров индивидуального, сиюминутного и судьбоносного цивилизационного выбора. Унаследованные от древних времен идеальные, фантазийные и материалистические картины реальности, героические и институциональные образцы, опытные способы и механизмы самодвижения, примеры и образы будущего, ценности и мораль предопределили главную логику преображения мира - путь гуманистического развития европейских народов, цивилизации планеты.

\section{Войны эпохи университетов: язык кухарок и князей}

Ученые-гуманисты, описывая этапы воинственной риторики и борьбы за справедливость, нашедшие отражение в героическом эпосе, легендах и поэтике, наполненных вдохновляющими примерами античной жажды жизни и движения, компарировали мораль, этику, нравственно-эстетические принципы и высокие образцы («прекрасное», «красота», «храбрость», «общее благо») или низменные, примитивные, приземленные ориентиры с пришедшими на смену эллинизму «срединными» веками, оценивали, прежде всего, состояние отношений людей, миропонимание и верования, язык, письменность, литературу, поэзию и искусство. Сравнительные документальные исследования показали: явившееся сквозь толщу многовекового забвения, как казалось, воплощало «одичание античного мира» и «варварство», отразило упадок нравов и сарказм, например в понятии «кухонная латынь» (coquinaria, culinaria latinitas).

Гуманист, родоначальник историко-филологической критики итальянский представитель исторической школы эрудитов XV в. Лоренцо Валла уподобил своего собрата по перу и противника - другого видного итальянского гуманиста, писателя и собирателя античных рукописей Поджо Браччоли повару, про- 
фессия которого считалась в те дни малопочетной. Здесь проявился характер природных механизмов соперничества, обострившего сердечное и умственное восприятие. Благоприобретенная функция волевой энергии и силы жизненных пониманий, защиты ценностей и их границ стала эталонной на пути духоспасительного интеллектуального самоохранения института идей и смыслов, преобразования мировоззренческого опыта в феномен социальной самоорганизации, лингвистического (языкового) саморегулирования и контроля - внутреннего неприятия, противодействия и соответствующей эпохе, вызывающей, унижающей критики, демонстрирующей идейный, идеологический конфликт.

Tак, с XVI века обращение к термину «кухонная латынь» служит знаком «испорченного языка, пренебрегающего правилами грамматики и словообразования классической латыни, <... прежде всего латинским языком церкви и средневековых университетов». Так часто называли «плохую латынь», которую, как было принято считать, использовали низшие классы в древнем Риме, и «средневековую монастырскую латынь в эпоху гуманизма». На эти образцы мышления и слова как самоценности и словоизъявления (языка, речи) обратили критическое внимание весьма незаурядные люди; среди них - немецкие гуманисты И. Рейхлин и У. Гуттен, а также названный «князем гуманности» Д. Эразм (Роттердамский).

Главной целью гуманистической деятельности один из великих ученых Северного Возрождения Дезидерий Эразм (1469[1466, 1467] - 1536 гг.) считал насущную необходимость возвращения в жизнь общества «высоких» образцов философского и литературного античного наследия. Подготовленный и изданный им на греческом языке оригинал Нового Завета был первым шагом к философско-критическому исследованию текстов Священного Писания. Еще один философ-гуманист Иоганн Рейхлин считается создателем фонетической системы чтения средневековых греческих текстов, названной впоследствии его именем, а третий - Ульрих фон Гуттен, - будучи рыцарем-гуманистом, стал одним из авторов и виновников нелицеприятной дискуссии по поводу издания знаменитой сатиры - книги «Письма темных людей», пародии на «кухонную латынь».

Книга «Письма темных людей» анонимно вышла в свет в Германии (в двух частях, в 1515 и 1517 гг.) и содержала острую критику, направленную против схоластики и клира. Этот труд группы гуманистов (У. Гуттен, К. Рубеан, М. Руф, Г. Буш) был связан с городским сообществом города Эрфурта - университетского центра и резиденции католического епископа. В этой книге пародировалась переписка невежественных, умственно и морально убогих монахов и теологов, которые представлялись как «темные люди», полные амбиций и откровенной злобы к свободной мысли. Обскуранты, случайно, по незнанию, принявшие книгу за работу своих идейных единомышленников, стали всеобщим посмешищем. Сам термин «обскурантизм», понимаемый сегодня как «мракобесие - враждебное отношение к просвещению, науке и прогрессу», является заголовком книги - Epistolæ Obscurorum Virorum («Письма темных людей») и в первоначальном смысле означал политику ограничения распространения знаний. Сюжет «Писем...» основывается на теме дискуссии И. Рейхлина и доминиканских монахов (например, И. Пфефферкорна) о том, следует или нет «сжигать все иудейские книги как нехристианские». В сочинении содержалась лаконичная программа гуманистического просветительства как основы освобождения страны от духовного насилия, ортодоксии и вымогательства папства.

Издание «Писем...» отразило глубину гражданской зрелости некоторой части людей высших слоев общества, которые из чисто идейных побуждений пытались изжить «традицию компромисса со старой церковью». Анонимность или 
псевдонимы были частым явлением «срединных» веков по причине того, что к реформаторам применялись суровые методы церковной инквизиции ${ }^{1}$ [История культуры...2001].

\section{Лингвокультурная безопасность}

Новое время внесло свои представления о движении мира и его картине, обогатилось новаторскими достижениями, критериями и оценками социальноисторического. Принято считать, что общественно-экономический расцвет по сравнению со временами предшествующих периодов стал результатом быстро сменяющихся этапов жизнеутверждающего восхождения светской науки. Отсюда, из практического опыта, по большей мере рационального осмысления природной действительности и ее законов пришло применение таких новых, иных критериев социально-исторического контента, как жизненная ценность, содержательность или полезность, непротиворечивость, подлинность или истинность, тождество, достаточность, а несколько позже - объективность, научность, достоверность, надежность (валидность). Однако и этот период развертывания, обретения новых смыслов и привлекательных образов будущего был достаточно сложен и непоследователен; он отражал переходное состояние человеческого ума и духа, изменчивость чувств и непрерывный поиск идей и знаний, опыта понимания и описания реальности. Новаторское в познании не сразу находило отклик у людей, сочетая рациональный, практичный выбор с иррациональными «всплесками» и сопутствующим им сопротивлением, получившими известность как «охота на ведьм».

Термин «Новое время» утвердился в научном обороте, но каждое государство вступало в эпоху со своими преимуществами, утратами и страхами, опираясь в ожиданиях не только на опыт преемственности, но и на «благородную идею», вымысел. В современном мире понятие «благородного вымысла» представляется, как пишет Никита Нанков ${ }^{2}$, «продуктивным по... причине, что... выступает неотъемлемой частью западной политической теории начиная с античности. Общество, отказавшееся во имя безопасности и общего блага от власти... сильного, выстраивает свои институты на основе законов, выражающих и закрепляющих общую волю народа», природу его свободного мышления и волеизъявления. Все было бы хорошо, если бы сказанное не расходилось с делом, а «восхождение» идей и смыслов «во имя безопасности и общего блага» касалось не только и исключительно «своих», «послушных», но и значительной части населения мира - абсолютно всех (!). Эту проблему ставит лингвистическая, лингвокультурная безопасность, в основании которой лежит комплексное изучение индивидуального и коллективного бессознательного как многомерного, оформляющего особый склад ума (менталитет) народов и организованных им обществ под влиянием закономерностей социальной, социокультурной самоорганизации, становления национальной идентичности и государственного суверенитета.

Целенаправленное исследование процессов осознания, «ментальности как базовой категории лингвистической безопасности означает изучение индивидуального или массового сознания, выраженного лингвокультурно окрашенными единицами знания» (Ю.Н. Караулов), которые, с одной стороны, воспроизводятся автохтонной логикой программного следования (априори)

\footnotetext{
${ }^{1}$ Hersh S.M. Selective Intelligence. - The New Yorker. 2003. May 12; https://ru.wikipedia.org/wiki/\%D0\% 9F\%D0\%B8\%D1\%81\%D1\%8C\%D0\%BC\%D0\%B0 \% D1\%82\%D1\%91\%D0\%BC\%D0\%BD\%D1\%8B\%D $1 \% 85 \_\%$ D0\%BB\%D1\%8E\%D0\%B4\%D0\%B5\%D0\%B9 (21.09.2017).

2 Никита Нанков (США) известен как специалист в области сравнительного литературоведения и визуальных искусств. См. http://magazines.russ.ru/nz/2012/2/n13.html (проверено 30.07.2018).
} 
этнонациональному и общественному опыту, а с другой - непрерывно, через управление видоизменяются повседневной единичной, частной практикой и организованной деятельностью больших масс людей, в реализации которых особое место занимает свободно избранный (навязанный) глобальной информационной сетью «образ будущего».

Анализ меняющегося - мультипликатирующего (умножающегося) - коллективного бессознательного или массового, глобального самосознания с трудом поддается непосредственному наблюдению (прямыми методами), но его можно изучать опосредованно - «косвенными методами... через язык» - носитель жизненных смыслов, «образа будущего» и их связей со способами достижения. Здесь «российская ментальность, в максимальной степени лишенная этнической окраски, формировавшаяся веками в результате взаимодействия множества этнических ментальностей, включает в себя весь положительный опыт этого взаимодействия» [Халеева 2006]. Принципиально оставляя за скобками дискуссию по проблеме ментальности, «лишенной этнической окраски», укажем, что статус русского языка закреплен Основным законом страны Конституцией РФ.

Конституция (1993 г.) устанавливает государственный статус русского языка на всей территории России (гл. 3 «Федеративное устройство», ст. 68, п. 1) и утверждает, что «республики вправе устанавливать свои государственные языки. В органах государственной власти, органах местного самоуправления, государственных учреждениях республик они употребляются наряду с государственным языком РФ» (ст. 68, п. 2). При этом Россия «гарантирует всем ее народам право на сохранение родного языка, создание условий для его изучения и развития» (ст. 68, п. 3). Расширительную трактовку это положение находит в ст. 69 той же главы, гласящей, что «РФ гарантирует права коренных малочисленных народов в соответствии с общепризнанными принципами и нормами международного права и международными договорами Российской Федерации». И далее, в главе 2 «рава и свободы человека и гражданина» (ст. 44, п. 1-3) находим: 1) «каждому гарантируется свобода литературного, художественного, научного, технического и других видов творчества, преподавания. Интеллектуальная собственность охраняется законом»; 2) «каждый имеет право на участие в культурной жизни и пользование учреждениями культуры, на доступ к культурным ценностям»; 3) «каждый обязан заботиться о сохранении исторического и культурного наследия, беречь памятники истории и культуры». Так, Конституция РФ, если не вдаваться в проблемы продуманности, глубины и ее соответствия современным реалиям страны, ее «дух и буква» достаточно широко определяют область упорядочения и развития культурно-языковых взаимоотношений - в местных сообществах, субъектах федерации, в России и в международном плане.

Однако на современной ситуации отражаются унаследованные неоднозначные результаты перестроечных ожиданий, мифов и прожектов «благородного вымысла», достаточно тревожных и не до конца пройденных и осмысленных реформ («шоковая терапия», «потерянное поколение», «утечка мозгов», дефолт, люмпенизация, прекариат, пр.), а также вызванных во многом именно ими следствий: духовной апатии и пассивности интеллектуальных сил, изменений в ценностной ориентации на изобретательство, общественно-полезный труд и творчество, утраты человеческого доверия к людям и власти, ценности качества трудового, профессионального капитала под влиянием его принудительного преображения и деформации, если не сказать деградации, например, трансформация «человека труда» - в «массового потребителя» услуг, шопоголика, др. 
Сегодня имеют место две противоположные четко выраженные тенденции - рождение нового типа высоко востребованных специалистов будущей «цифровой экономики» и одновременно существование их антипода - прекариата социального слоя (класса) работников с временной или частичной занятостью, которая носит постоянный, устойчивый характер. Преодоление болезненных для российской ментальности и самоидентификации (личной, многонациональной, православной, государственной, гражданской) материальных, территориальных и человеческих потерь - дело не одного поколения, поскольку современная мировая цивилизация в сложившихся социально-исторических условиях дезинтеграции скатилась к закономерной и малоперспективной геополитической парадигме однополярности, взаимных санкций, дипломатических демаршей и угроз.

Современные исследователи лингвистической безопасности констатируют, что произошло «переконструирование языковой ситуации на... постсоветском пространстве. Из всех республик бывшего СССР - ныне независимых государств - только в Белоруссии русский язык получил статус государственного наряду с титульным белорусским языком. В других же странах СНГ и Балтии русский язык оказался на положении языка национального меньшинства» [Халеева 2006], «изгоя», но на котором пока еще говорят как значительная часть населения и молодежи, так и государственные политики и местные чиновники. Это ставит важную проблему ответственности за будущее, особенно в связи с распространяющимися вопиющими случаями непрофессионализма и системных нарушений, игнорирования правил и норм русского литературного языка; двусмысленности формулировок информационного контента, примеров волюнтаризма, лексических, лингвистических и семантических приемов откровенной провокационности, лицемерия и лжи, граничащих с непроизвольно (или сознательно?) допускаемым (или формируемым?) неуважением и отторжением образцов. Эти явления достигли стадии, когда «ответственность... выходит за рамки культуры речи и грамотности как критерия человеческой культуры» [Трофимова 2012: 24].

Лингвистическая безопасность сегодня как в России, так и в глобальном мире представляет многомерное общественное явление. Указанное подразумевает актуальность - насущную необходимость, полезность и своевременность исследования широчайшего многообразия проблем реальности. Совокупность тематических направлений, организованных ими проблемных групп и полей призваны рассмотреть множество вопросов правил, норм и практик «научения», укоренения эталонных практик доброжелательного межличностного общения и уважительного делового, партнерского взаимодействия; этически оправданных и эстетически выверенных форм коммуникации через литературу, кинематограф, СМИ, Интернет и иных; средств противодействия злостным нарушителям цивилизационных «церемоний».

Термин «лингвистическая безопасность» получил признание и касается личной и коллективной (общественной) ответственности - морально-этической, гражданской, административной, уголовной [Горбаневский 2002; Галяшина 2006], информационной (СМИ, TV, ИКТ, Интернет), а также всех тех, кто имеет влияние на состояние души и воззрений человека, атмосферу в обществе и мире - от родителей, педагогов, писателей, журналистов, людей искусства и ученых до общественных деятелей, политиков и населения, гражданского общества как самого широкого представительства неравнодушных людей, а также власти, за неписаное и данное, написанное слово. Это имеет особое значение при обосновании научных парадигм и концепций, описании современной картины мира, цивилизации и состояния текущей реальности, выборе идей, стратегий и док- 
трин, образов «светлого завтра», методов идеологического влияния и результативного целеполагания. Указанное определяет форму и содержание проектов, программ социального, экономического и межстранового, геополитического, демографического и научно-технического управления (менеджмента). Язык, лингвистическая безопасность как одна из духовно-интеллектуальных, «высоко» и социально самоорганизующихся, динамично развивающихся сфер жизненного пространства человека, народов и наций требуют профессиональной координации и перспектив общественного и государственного строительства, регулирования механизмов взаимодействия населения, бизнеса и власти прежде всего в областях, ответственных за гуманистический, психологический и трудовой контент, за развитие широких неокорпоративных (а не узкогрупповых), новых рыночно-социальных и иных отношений, что особенно важно на этапе зарождающегося «цифрового» общества.

Для продуктивного движения абсолютно необходимы объединяющие, а не конфликтующие смыслоценностные личные и коллективные, этические и эстетические ориентиры, закладывающие основы гуманистического со-бытия, профессиональные новаторские подходы и качественно проработанные законы, принципы и моральные нормы, корректные научные требования и стандарты: образовательные, медицинские, промышленные, торговые, рыночные и иные высоко востребованные продукты интеллектуальной деятельности людей.

Многое из сказанного уже существует в ментальности, традициях и нормах религиозных, культурных и общественных отношений. Решение значительного числа актуальных проблем отражено в официальных юридическо-правовых, дипломатических и международных документах, но большая их часть, ввиду стремительно меняющихся условий жизни, еще ожидает формализации, четкого описания конкретных позиций, учета требований разных слоев (классов, сословий, пр.) населения к себе подобным, бизнесу и власти; суверенных государств - к мировому сообществу и его институтам с опорой на современный цивилизационный «образ будущего», высокие требования и новаторство по его созданию.

Отсюда оценка лингвистической безопасности как одной из определяющих системообразующих составных частей национальной (общественной) безопасности, включающей решение многообразия проблем разных степеней сложности и уровней, - от мировоззренческой, идеологической (идейной, патриотической), трудовой до социокультурной, гуманистической, деловой сфер (бизнес, предпринимательство), сфер гражданского и государственного строительства, власти и управления. Каждая из проблем актуализирует и предусматривает постановку задач обеспечения прав, свобод и защиты населения - психолингвистической, медицинской, демографической, продуктовой и экологической; отстаивание этнонациональных интересов, в т.ч. безопасности, в информационной, производственной, технической, технологической, коммуникационной (СМИ, $T V$, Интернет) отраслях, в областях ИКТ, организации труда, творчества и искусства, в сферах науки и образования, просвещения и воспитания поколений. Состояние лингвистической безопасности и данные исследований необходимо особым образом учитывать при разработке, принятии и реализации управленческих решений, поскольку большинство из них затрагивают глубинные чувства большого числа носителей фундаментальных социально-исторических, межконфессиональных, межкультурных и многонациональных интересов людей и сообществ мира; имеют статус значимых для социального государства, каким провозглашается Россия, являются резонансными, проактивными и катастрофоустойчивыми как для настоящего времени на просторах нашей страны, так и для будущего 
всей планеты на пути цивилизованного движения по сохранению всемирного наследия - достижения понимания, согласия и гарантий мира и глобального со-бытия.

\section{Список литературы}

Галяшина Е.И. 2006. Лингвистика экстремизма: в помощь судьям, следователям, экспертам. М.: Юридический мир. 96 с.

Горбаневский М.В. 2002. Будь осторожен, выбирая слово! - Цена слова: Из практики лингвистических экспертиз текстов СМИ в судебных процессах по защите чести, достоинства и деловой репутации. 3-е изд., испр. и доп. М.: Галерия. С. 15-36.

Иноземцев В.Л. 1999. Расколотая цивилизация. М.: Наука. 724 с.

История культуры стран Западной Европы в эпоху Возрождения (под ред. Л.М. Брагиной). 2001. М.: Высшая школа. 479 с.

Трофимова Г.Н. 2012. Лингвистическая безопасность: к проблеме толкования. - Вестник РУДН. Сер. Русский и иностранные языки и методика их преподавания. № 1. С. 24-29.

Халеева И.И. 2006. Лингвистическая безопасность России. - Вестник Российской академии наук. Т. 76. № 2. С. 104-111.

KUVAKOVA Irina Mihailovna, Cand.Sci. (Soc.), Associate Professor of the Russian Academy of Entrepreneurship (15 Malaya Andron'yevskaya St, Moscow, Russia, 109544; kuvakovaim1999@mail.ru)

USTINKIN Sergei Vasil'evich, Dr.Sci. (Hist.), Professor; Dean of the Faculty of International Relations, Economy and Management; Professor of the Chair of International Relations and Political Science, Dobroljubov State Linguistics University of Nizhny Novgorod (31a Minina St, Nizhny Novgorod, Russia, 603155); Director of Volga branch of the Federal Center of Theoretical and Applied Sociology, Russian Academy of Sciences (4 Holodnyi Lane, Nizhny Novgorod, Russia, 603000; sv.ustinkin@gmail.com)

\section{LANGUAGE AS AN INSTITUTE AND A TOOL OF MENTAL AND SELF-STRUCTURING OF THE FUTURE WORLD}

Abstract. In the article, language is considered as the mechanism of social self-organization. Word is the cornerstone of formation of the human relations, rules of the neighborhood and social actions. The authors analyze a problem of linguistic safety and the related aspects of the development of society.

Keywords: linguistic safety, language, sense, social processes, political process 